\title{
Enlargement of the Veins in a Sylvian Fissure Mimicking a Subarachnoid Hemorrhage
}

\author{
Hiroaki Iwasaki
}

Key words: headache, subarachnoid hemorrhage, Sylvian fissure, superficial middle cerebral vein, deep middle cerebral vein, neuroimaging

(Intern Med 56: 2545-2546, 2017)

(DOI: 10.2169/internalmedicine.8444-16)
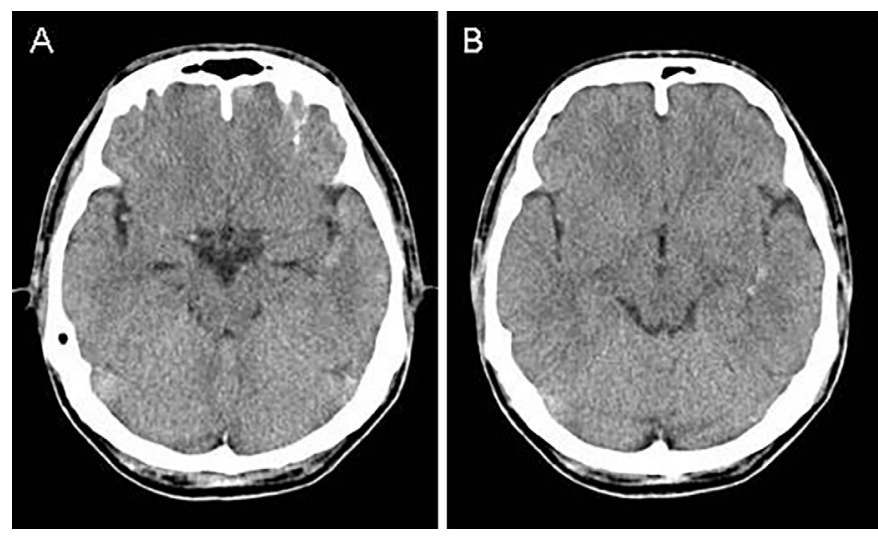

Picture 1.
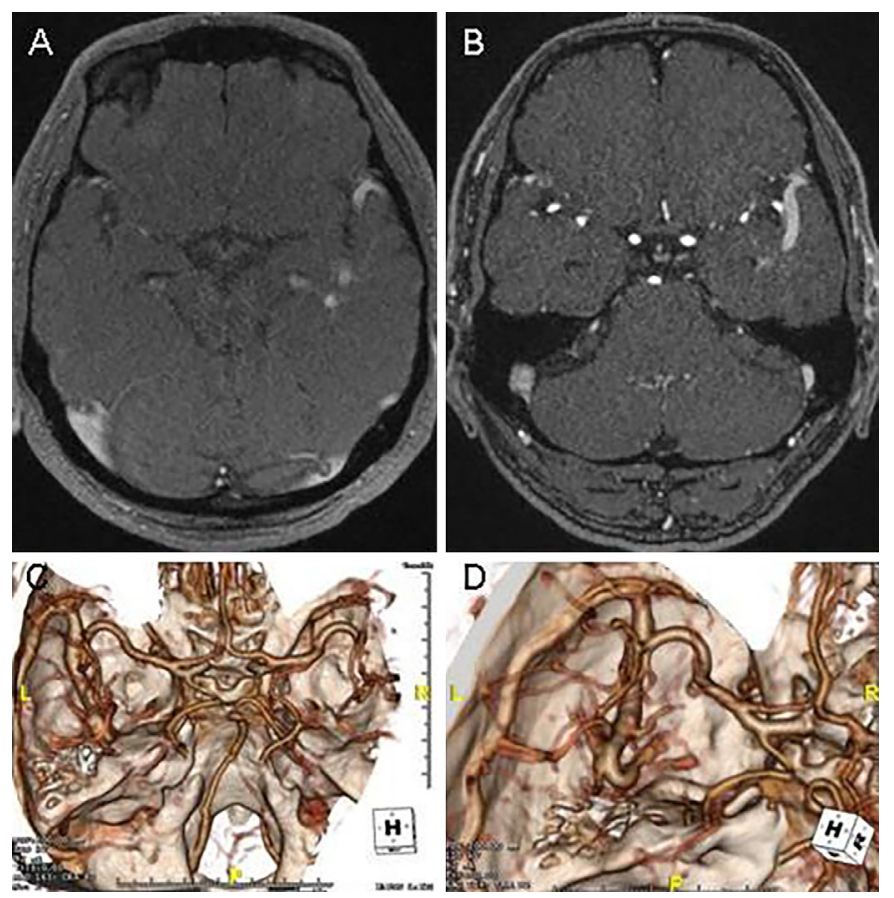

Picture 2.

Department of Internal Medicine, Toshiba Rinkan Hospital, Japan

Received: October 22, 2016; Accepted: January 20, 2017; Advance Publication by J-STAGE: August 21, 2017

Correspondence to Dr. Hiroaki Iwasaki, iwasaki.har@gmail.com 

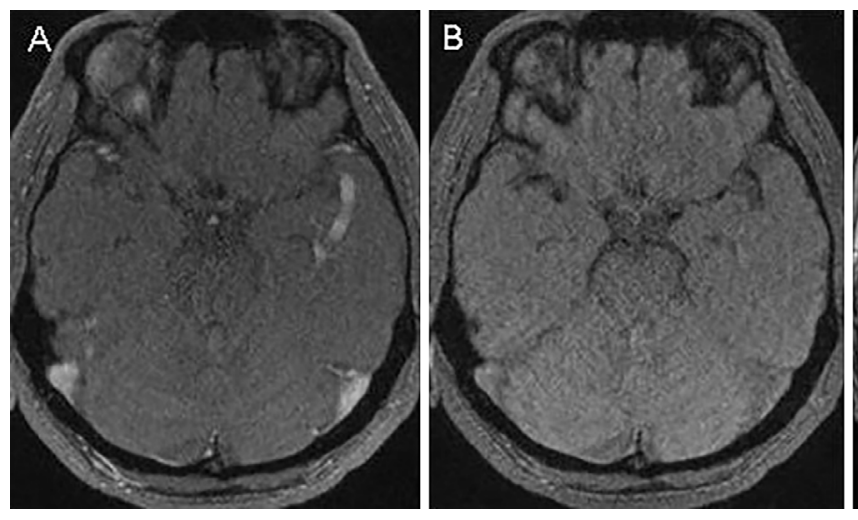

Picture 3.

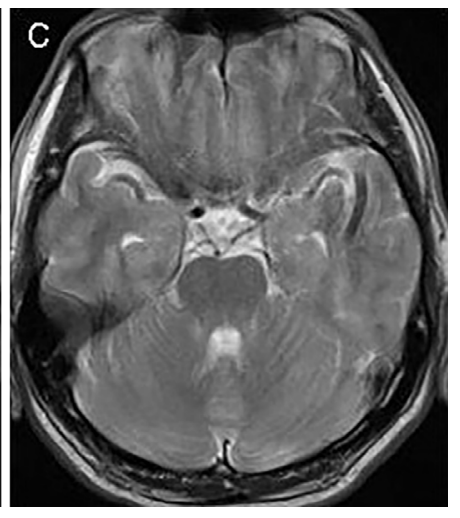

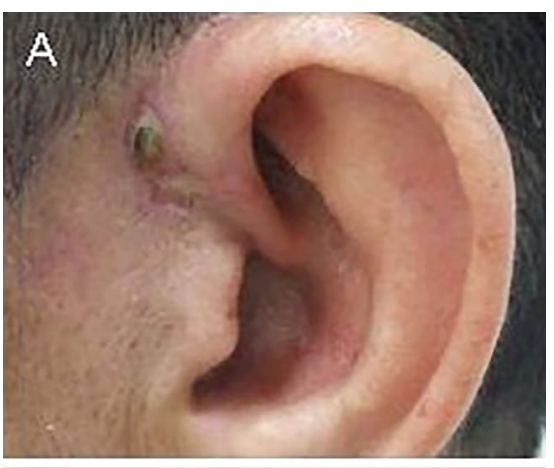
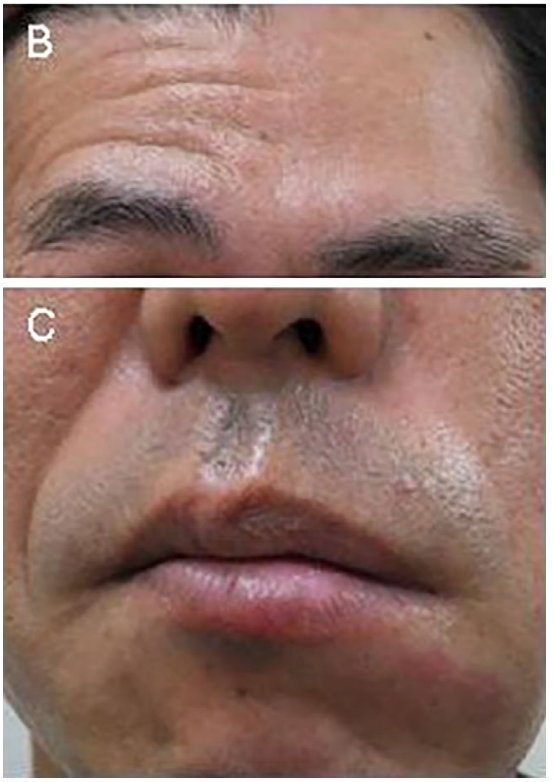

Picture 4.

A 45-year-old man visited our hospital following the experience of his first uncontrollable headache - which was not a migraine- or tension-type headache - which occurred despite treatment with non-steroidal anti-inflammatory drugs. A physical examination revealed no neurological abnormalities; however, non-enhanced computed tomography revealed a high-density area in the left Sylvian fissure (Picture 1). Advanced neuroimaging revealed a subarachnoid hemorrhage $(\mathrm{SAH})$ - the findings of which were identical to the enlargement of the veins in the fissure (Picture 2). Signal hypointensity of the corresponding region was noted on both T1- and T2-weighted magnetic resonance imaging this was likely due to calcification and/or multiple thrombosis of the vessel wall due to the stagnation of blood flow concomitant with local inflammation and a hypercoagulable state (Picture 3). A diagnosis of Ramsay Hunt syndrome was subsequently made based on the development of left peripheral facial palsy, accompanied by ipsilateral herpetic vesicles surrounding the ear and mouth (Picture 4). The veins in the Sylvian fissure have two drainage pathways: 1) the superficial middle cerebral vein; and 2) the deep middle cerebral vein axes. The veins display a large degree of variation due to the prenatal development of anastomoses between the cavernous, sphenoparietal and superior petrosal sinuses $(1,2)$. Thus, the enlargement of the veins in the Sylvian fissure should be considered in the differential diagnosis of SAH using neuroimaging.

The author states that he has no Conflict of Interest (COI).

\section{Acknowledgement}

The author thanks Dr. Shinya Yamada (Department of Neurosurgery, Toshiba Rinkan Hospital) and Dr. Michitake Kazuno (Department of Neurosurgery, Fujisawa Neurosurgical Hospital) for their collaboration.

\section{References}

1. Suzuki Y, Matsumoto K. Variations of the superficial middle cerebral vein: classification using three-dimensional CT angiography. AJNR Am J Neuroradiol 21: 932-938, 2000.

2. Tanriover N, Rhoton AL Jr, Kawashima M, Ulm AJ, Yasuda A. Microsurgical anatomy of the insula and the sylvian fissure. $\mathbf{J}$ Neurosurg 100: 891-922, 2004.

The Internal Medicine is an Open Access article distributed under the Creative Commons Attribution-NonCommercial-NoDerivatives 4.0 International License. To view the details of this license, please visit (https://creativecommons.org/licenses/ by-nc-nd/4.0/).

(C) 2017 The Japanese Society of Internal Medicine Intern Med 56: 2545-2546, 2017 